\section{Basrah Journal of Agricultural Sciences}

E-ISSN: 2520-0860

ISSN $1814-5868$

Basrah J. Agric. Sci., 34(Special Issue 1), 157-170, 2021

\title{
Drone Payload and Flying Speed Effects on Rotor Blades' RPM and Traveling Pattern for Agricultural Chemical Spraying
} Siti A. Ismail ${ }^{1 *}$, Azmi Yahya ${ }^{1}$, Ahmad S. Mat Su ${ }^{2}$, Norhayu Asib ${ }^{3}$, Anas M. Mustafah ${ }^{1}$

${ }^{1}$ Department of Biological and Agricultural Engineering, Faculty of Engineering, Universiti Putra Malaysia, Malaysia.

${ }^{2}$ Department of Agricultural Technology, Faculty of Agriculture, Universiti Putra Malaysia, Malaysia.

${ }^{3}$ Department of Crop Protection, Faculty of Agriculture, Universiti Putra Malaysia, Malaysia

*Corresponding author E-mail:sitiamni@gmail.com

Received 27 August 2019; Accepted 19 July 2021; Available online 20 August 2021

\begin{abstract}
The sprayed chemicals by drones have been widely reported to be off-targeted and not uniformly distributed. This study aims to evaluate the drone blade's revolutions per minute (RPM) and its travelling pattern at different payloads and flight speeds. The obtained results were used to relate to the potential effects on the quantity and quality of spraying. In a test flight on an area of $1000 \mathrm{~m}^{2}$, a hexacopter, Advansia A1 was tested in 6 different flying paths of $56 \mathrm{~m}$ length. The drone was set to fly at 5 payloads $(10,8,6,4$,

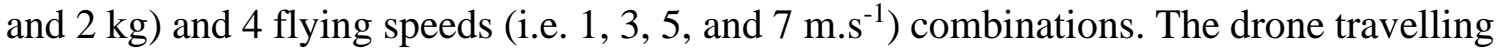
pattern and individual rotor blade rpm at each payload-flying speed combinations were analysed. From the result, the RPM of each rotor blade were found to decrease by 14 to $20 \%$ as the payload was decreased from $10 \mathrm{~kg}$ to $0 \mathrm{~kg}$. Thus, in actual spraying activities, the changes in RPM could produce a downwash airflow pattern that continually varies from starting point up to the finishing point that would effect on pesticide's distribution along the flying path. On drone travelling pattern, at higher flying speed, a much lesser time and distance was required for the drone to be stabilized to the targeted speed. This relates to the longer time needed by the drone to accelerate and decelerate. The average real speed of the drone was notably reduced to $0.96,2.72,3.83$ and $4.05 \mathrm{~m} . \mathrm{s}^{-1}$, in which, it was, far less than the initial specified speed set at $1,3,5$, and $7 \mathrm{~m} \cdot \mathrm{s}^{-1}$, respectively. The drone flying pattern during spraying needs to be considered for application rate determination to avoid for the crops to be under or over pesticide applications. The obtained finding is remarkably critical and useful in ensuring the efficiency of agricultural chemical spraying activities using drone.
\end{abstract}

Keywords: Aerial spraying, Agricultural drone, UAS, Flying behavior, Spraying management.

\section{Introduction}

Drone utilisation as a pesticide application technology has been widely used in South East Asia, with a very significant proportion of treated agricultural areas. It was started in 1990 by Yamaha Corporation in Japan with the first unmanned aerial vehicle for pesticide application technology, and it has evolved rapidly and made considerable progress with the development of different types of drones for spraying a variety of crops. Because of its advantages, the drone has been widely used. Compared to the conventional practices using knapsack, with regard to the deployed spraying method, flight pattern and spray 


\section{Ismail et al. / Basrah J. Agric. Sci., 34(Special Issue 1): 157-170, 2021}

width, the drone is capable to increase the field capacities and application rate at 2.0 to 4.5 $\mathrm{ha} / \mathrm{hr}$ and 14.0 to $39.0 \mathrm{l.ha}^{-1}$, respectively (Giles \& Billing, 2014). Other advantages of it are replacing human labour, overcoming high human variables, reducing pesticide exposure, and high accuracy in a site-specific application. It is also good for vector control in the areas that are not easily reachable by personnel (Meivel et al., 2016; Huang et al., 2009; Faiçal et al., 2017; Morley et al., 2017).

The pesticide application technology has played a key role in pest management. Appropriate selection of equipment and its technique of application are crucial to the success of any pest control operation. A successful pest control operation depends greatly on the pesticide quality, application timing and application quality. Although a good quality pesticide and right timing are met, it may not give an effective treatment unless the pesticide is applied properly. Therefore, to reach the quality of application, it has become the main purpose of any technology used for the sprayed pesticide to reach the target uniformly at the proper dosage, proper droplet size and proper density. Improper and excessive use of pesticide would result in environmental hazards and a serious threat to the safety of people nearby.

Admittedly, the main challenge in agricultural chemical spraying is that the application technique should be ideally precise to meet the spray target at the earlier set application rate with minimum drift (Doruchowski, 2013). Few works had been conducted to determine the deposition of droplets with spraying of drones. The finding from Wang et al. (2017) found that the pesticide application of drone was on low precision and at an unsatisfactory level. The droplet deposition pattern was found scattered both in lateral and longitudinal directions ( $\mathrm{Su}$ et al., 2018). The research had proved the earlier finding done by Qin et al. (2016) and Zhang et al. (2016) who evaluated the spray deposition from drones in paddy and citrus crops. It has been noted that the environmental condition, spray chemical, leaf properties and spray system had influenced the spray deposition, however, the usage of drone in spraying has added another factor where the effect of rotor air flow or downwash produced by rotational blades in spraying had caused the droplets to drift in all directions in an uncontrollable manner, which consequently affected the deposition pattern and resulted in pesticide waste (He et al., 2017; Wang et al., 2017; Zhang et al., 2017).

The downwash is defined as the deflection of the airstream due to aerodynamic action of the blades, as part of the process of providing lift to the drone. The downwash created is unique for every drone due to its different blade configurations. According to Teske et al. (2018), each drone has its own release height, flight speed, crosswind and weight limit that need to be considered to achieve accurate and successful spraying. Understanding how the technology works in the first place is crucial as a basic knowledge to manage and handle pesticide and calibrate the equipment. Therefore, the objective of this test is to understand how the rotation of blades (RPM) cum the contributor of downwash responds dynamically as the payload and flight speed change. The travelling pattern of the drone when responding to the speed set by the ground pilot that may help in optimising the pesticide application is also being determined. The data gathered in this paper will then be later used in acquiring the downwash flow field and droplet deposition using the newly developed indoor testing facility for agricultural chemical spraying with the drone. In addition to getting the correlation between 
Ismail et al. / Basrah J. Agric. Sci., 34(Special Issue 1): 157-170, 2021

the downwash flow field and the droplet deposition, this final result may lead to the optimum application parameters and application of pesticides. It is hoped that by reaching the ultimate result, it may become a basis in setting the Best Management Practices (BMP) for drone application in spraying.

\section{Materials \& Methods}

The test took place at the football field of the Universiti of Putra Malaysia sports complex (GPS: 2.9852477, 101.7250353). The research area was around $1000 \mathrm{~m}^{2}$ with a total of 6 routes (replications). Each line is 56 metres long. It was predetermined by considering drone accuracy and safety (Fig. 1). The field test was consistently conducted between 6:30 and 8:30 a.m. The recorded wind was within the range of 2 to $3 \mathrm{~km} / \mathrm{h}$ (calm condition). Such environmental condition is relatively easy to maintain the drone's flying stability and furthermore, to imitate the actual process of pesticide spraying under minimum spray drift.

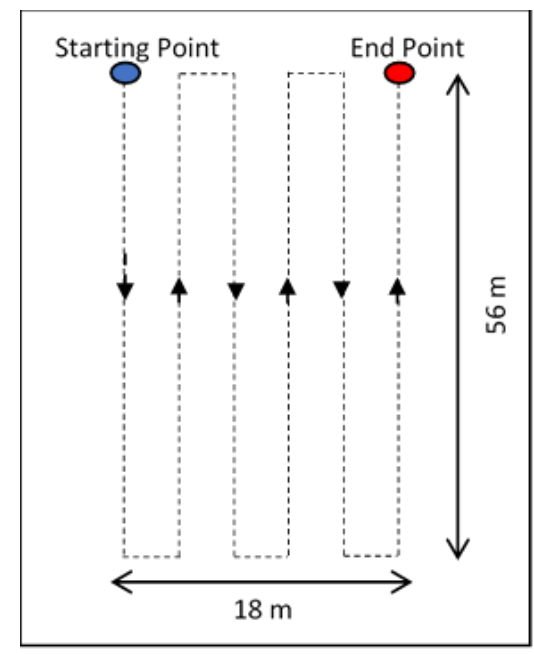

Fig. (1): Drone's route during field test

\section{Drone specification}

A hexacopter agricultural drone with a maximum payload of $10 \mathrm{~kg}$ had been used in this field test. The drone's detailed specifications are depicted in fig. (2) and table (1). The flight was automatically controlled using the remote controller under the automatic flying mode.

\section{Drone setting}

The test area was first scouted to make sure there was no presence of flying obstacles. The drone was set to fly autonomously throughout the test. The height of the drone was set at 2.5 $\mathrm{m}$ on all trips. The speeds were varied at 1,3 , 5 , and $7 \mathrm{~m} . \mathrm{s}^{-1}$ while the payloads were varied at $0,2,4,6,8$, and $10 \mathrm{~kg}$. The distance between the lines was set at 3 metres. While doing the test with the drone, the spraying system was disabled. 


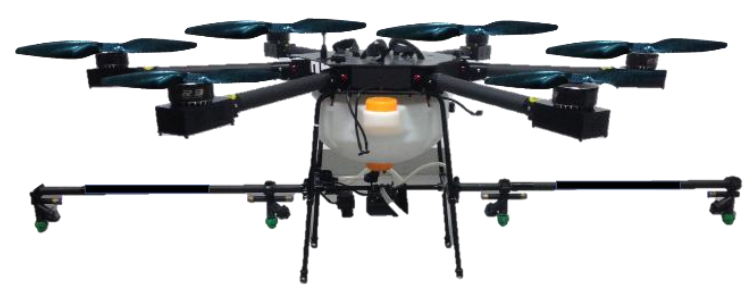

(a)

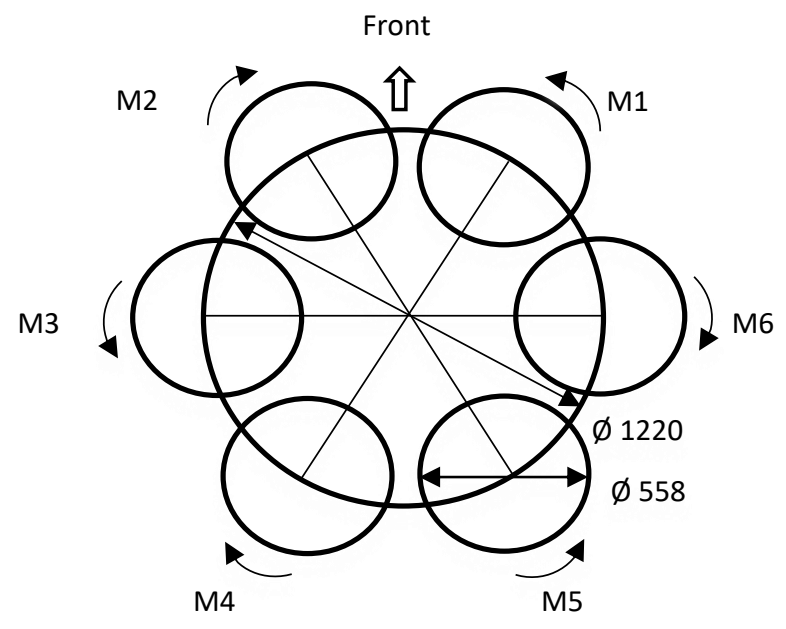

(b)

Fig. (2): (a) Picture of actual drone (b) Diameter ( $\mathrm{mm}$ ) of propellers and wheelbase of drone.

Table (1): Drone technical specifications.

\begin{tabular}{cc}
\hline Model & Advansia A1 \\
\hline Manufacturer's name & Advansia Sdn Bhd \\
\hline Year manufactured & 2015 \\
\hline Number of propellers & 6 (Hexa Drone) \\
\hline Type of Propellers & T2255 - Carbon Fibre straight propellers \\
\hline Type of Brushless Motor & JMR 6215 - KV 170 \\
\hline Power source & Poly Lithium Battery x 2 (16000 mAh) \\
\hline Maximum payload & $10 \mathrm{~L}$ \\
\hline Gross aircraft weight & $25 \mathrm{~kg} \mathrm{(maximum} \mathrm{with} \mathrm{payload)}$ \\
& $15 \mathrm{~kg}$ ( without payload) \\
\hline
\end{tabular}

\section{Data extraction}

The data were extracted from the flight controller using an in-house developed interfacing software. The data were recorded for every $0.5 \mathrm{~s}$. For every combination of payload-speed, the data of the drone with regard to coordinate (longitude, latitude) and per cent throttle for each rotor motor were extracted from the software. The changes of per cent throttle motor of the drone while travelling were observed for each travelling line. For each line, 10 points were extracted within stabilisation speed of the drone. The six lines represented the 6 replications for each combination of payload-speed. To observe the effective travelling time and the travelled distance of the drone, the information of the coordinate, duration and speed were used. The results on each of the observations are being discussed in the respective sections below.

\section{Data analysis}

The data percentage (\%) of motor throttle was manually extracted from the software and converted by using the information provided by the manufacturer in order to get the motor rotational speed. From the information, Eq. (1) was developed and used to convert the recorded motor throttle readings to motor rotational speed. The formula of application rate Eq. (2) was used in determining the 
Ismail et al. / Basrah J. Agric. Sci., 34(Special Issue 1): 157-170, 2021

application rate based on the speed of the of variance (ANOVA) and Tukey significant drone. All the extracted dataset was further test using PC SASv9.4 software.

analysed for the descriptive statistics, analysis

$$
Y=-0.1971 x^{2}+52.65 x+2106
$$

Where;

$\mathrm{Y}=$ Motor rotational speed, $\mathrm{rpm}$

$\mathrm{X}=$ Motor throttle, $\%$

$$
\text { Application rate }(\mathrm{l} / \mathrm{ha})=\frac{\text { Flow rate }\left(\frac{\mathrm{l}}{\mathrm{min}}\right) \times 10,000}{\text { Swath Width }(\mathrm{m}) \times \text { Speed }\left(\frac{\mathrm{m}}{\mathrm{min}}\right)}
$$

\section{Result \& Discussion}

Rotor RPM at various payloads and forward speed and its potential effect towards downwash pressure and pesticide distribution.

The data were analysed using PC SAS software to investigate the changes of RPM for each rotor (M1 to M6) as the payload and speed changed. It has been found that by considering $\mathrm{P}<0.05$ as significant, all rotors were significantly affected by the changes of payloads and speed (Table 2). All rotors showed an increase in RPM value as the payload increased. Based on Fig. (3), the value of RPM increased by about $14-21 \%$ from carrying $0 \mathrm{~kg}-10 \mathrm{~kg}$ payload. This finding matches the aircraft lifting theory which indicates that more thrust production is needed to counter the gravitational force effect as the total payload weight of the whole drone is increased. Thus, to increase the thrust, the RPM of all blades should be increased to push more air downwards. At the same time, while maintaining the thrust, the RPM of the blades would also react to the earlier set speeds so that the forward movement could be created.

Table (2): Relationship between rotor motor RPM with payload and speed.

\begin{tabular}{cccccccc}
\hline & \multicolumn{7}{c}{ Test of Significance, $\mathrm{P}_{\mathrm{r}}>\mathrm{F}$} \\
\cline { 2 - 8 } & $\mathrm{M} 1$ & $\mathrm{M} 2$ & $\mathrm{M} 3$ & $\mathrm{M} 4$ & $\mathrm{M} 5$ & M6 & AVG \\
\hline Payload & $<.0001$ & $<.0001$ & $<.0001$ & $<.0001$ & $<.0001$ & $<.0001$ & $<.0001$ \\
\hline Speed & $<.0001$ & $<.0001$ & $<.0001$ & $<.0001$ & 0.0007 & 0.0005 & $<.0001$ \\
\hline
\end{tabular}

Relating this behaviour to the actual process in the field, the drone is usually being filled at its full tank capacity $(10 \mathrm{~kg})$ and flies at the speed that has been set by the ground pilot. As the operation is running, the tank will eventually be decreasing its capacity while conducting the spraying operation in the field. Thus, the RPM of all blades and the thrust created will follow to decrease, although the flying speed is maintained at a constant. Based on the graph, in the actual operation, it was expected that the downwash airflow pattern 
Ismail et al. / Basrah J. Agric. Sci., 34(Special Issue 1): 157-170, 2021

was continuously changing from the starting to the end point which might consequently affect the distribution of the pesticide as the drone travelled. This finding is in line with Berner \&
Chojnacki (2017) and Berner (2018) who had concluded that the flow field produced from rotational blades had changed the volume of the pesticide that subsided on the plants.
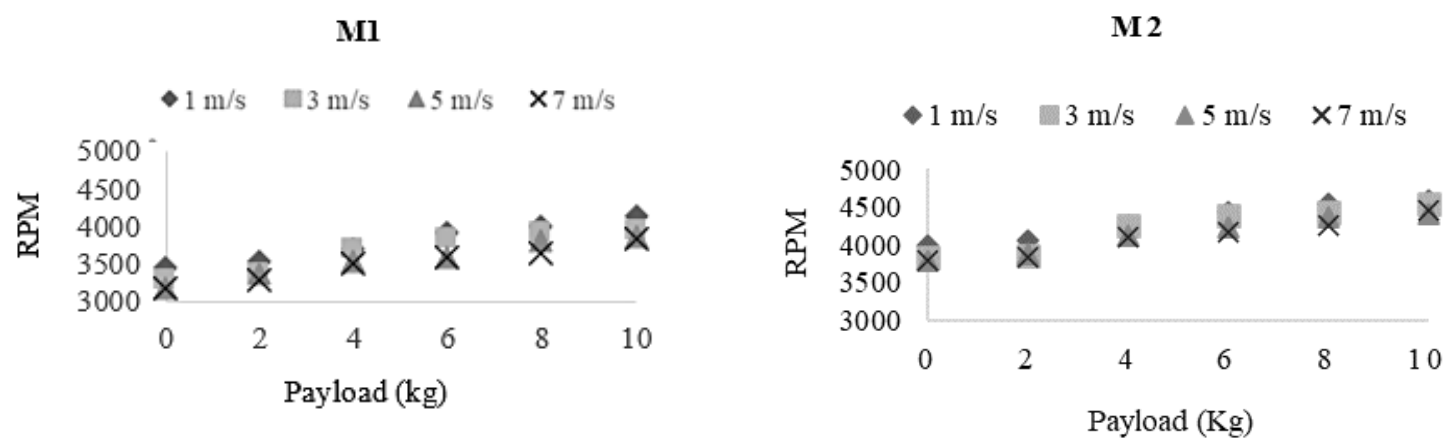

M3
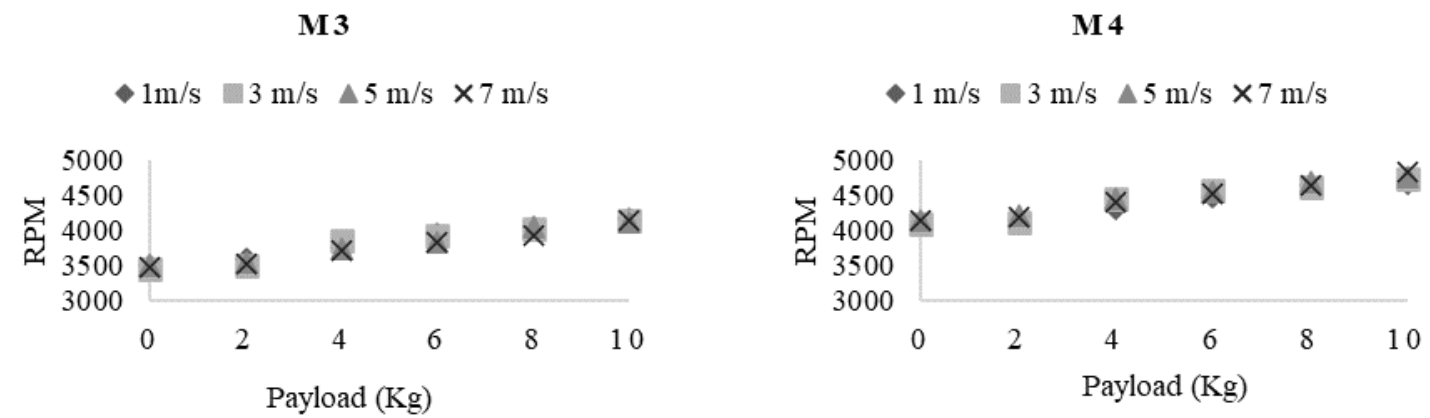

M5
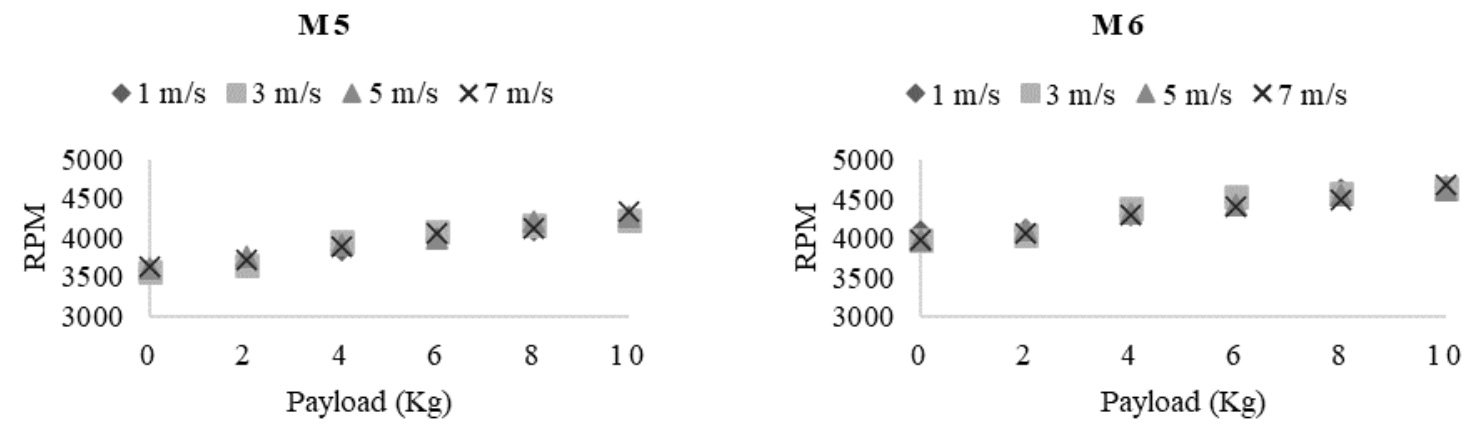

Fig. (3): Respond of rotor RPM towards payload at different forward speed.

\section{Effective flying speed.}

It is important to observe the response of the drone during flying in reaching the target speed set by the ground pilot. As for spraying application, the speed of the drone is very important in determining the drone application rate $\left(1 . h a^{-1}\right)$ in a way of preventing the occurrence of under or over fertiliser application. From the research it was observed that, as the drone started to travel, there were 3 phases of movement (Fig. 4), i) Phase 1 - the phase where the drone accelerated to reach the 
Ismail et al. / Basrah J. Agric. Sci., 34(Special Issue 1): 157-170, 2021

target speed ii) Phase 2 - the phase where the drone flew at the target speed and iii) Phase 3 - the phase where the drone decelerated as it approached the end of flying line. From the data, it has been found that at phases (i) and (iii), the drone was flying not at a constant speed. It is worth to discover the time taken and distance travelled in each phase. Thus, the speed of the drone was tracked down for every $0.5 \mathrm{sec}$ interval as it flew from $0 \mathrm{~m}$ (start of the line) to $56 \mathrm{~m}$ (end of the line) at all payloadspeed combination. From the data, the time taken by the drone during i) accelerating (phase 1) ii) travelling at the target speed (phase 2) and iii) decelerating (phase 3) and total time to finish the line was gathered and analysed using PC SAS software. The time taken at each phase then was related to payloads and travel speed set. The result from the analysis has shown that the time taken at all phases and the total time taken to finish one line was significantly affected by the set flying speed $(\mathrm{P}<0.05)$ (Table 3$)$ except column (d) that was slightly affected by the payload.

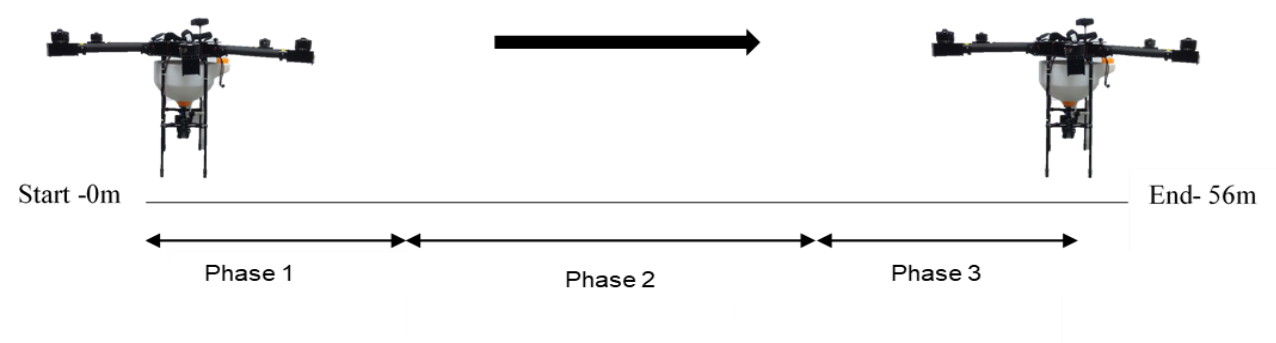

Fig. (4): i) Phase 1- phase where the drone accelerates to reach the target speed ii) Phase 2 phase where the drone flies at the target speed and iii) Phase 3- phase where the drone decelerates as it reaches the end of the line.

Table (3): Relationship between time taken with payload and speed.

\begin{tabular}{ccccc}
\hline & $\begin{array}{c}\text { The time taken } \\
\text { by the drone to } \\
\text { accelerate }\end{array}$ & $\begin{array}{c}(\mathrm{b}) \\
\text { Total time of } \\
\text { the drone } \\
\text { flying at the } \\
\text { target speed } \\
(\mathrm{sec})\end{array}$ & $\begin{array}{c}\text { The time taken } \\
\text { by the drone to } \\
\text { decelerate }\end{array}$ & $\begin{array}{c}(\mathrm{d}) \\
\text { Total time } \\
\text { taken to finish } \\
\text { one line }\end{array}$ \\
\hline Payload & 0.5148 & 0.8239 & 0.2281 & $(\mathrm{sec})$ \\
\hline Speed & $<.0001$ & $<.0001$ & $<.0001$ & $<.0026$ \\
\hline
\end{tabular}

As has been shown in table (4), column (a), to reach the target speed $\left(1,3,5\right.$ and $\left.7 \mathrm{~m} . \mathrm{s}^{-1}\right)$ the drone took about 4.83 to $6.36 \mathrm{~s}$. As the drone reached the target speed, it then took around $47.67 \mathrm{~s}$ to maintain at the target speed at $1 \mathrm{~m} . \mathrm{s}^{-1}, 10.56 \mathrm{~s}, 2.89 \mathrm{~s}$ and $1.39 \mathrm{~s}$ in maintaining speed at 3,5 and $7 \mathrm{~m} \cdot \mathrm{s}^{-1}$ respectively. As the drone approached the end of the line $(56 \mathrm{~m})$, the drone decelerated and it took around 2.75 to $5.97 \mathrm{~s}$ before the end of the line. As these progressed, the actual total time 
taken to finish one line is listed in table (4)

column (d).

Table (4): Average time taken along the line.

\begin{tabular}{ccccc}
\hline Desired Speed & $\begin{array}{c}\text { The time taken } \\
\text { by the drone to } \\
\text { accelerate }\end{array}$ & $\begin{array}{c}\text { Total time of } \\
\text { the drone } \\
\text { flying at the } \\
\text { target speed } \\
(\mathrm{sec})\end{array}$ & $\begin{array}{c}\text { The time taken } \\
\text { by the drone to } \\
\text { decelerate }\end{array}$ & $\begin{array}{c}(\mathrm{d}) \\
\text { Total time } \\
\text { taken to finish } \\
\text { one line } \\
(\mathrm{a}+\mathrm{b}+\mathrm{c}) \\
(\mathrm{sec})\end{array}$ \\
\hline $\mathbf{1}$ & $\begin{array}{c}\left.\mathrm{s}^{-1}\right) \\
\mathbf{3}\end{array} \mathbf{s e c}^{4.83 \pm 2.39 \mathrm{a}}$ & $\begin{array}{c}47.67 \pm 2.77 \mathrm{a} \\
(\mathrm{sec})\end{array}$ & $2.75 \pm 1.92 \mathrm{a}$ & $55.25 \pm 1.93 \mathrm{a}$ \\
\hline $\mathbf{5}$ & $6.36 \pm 0.69 \mathrm{~b}$ & $10.56 \pm 0.88 \mathrm{~b}$ & $3.25 \pm 0.77 \mathrm{a}$ & $19.83 \pm 0.51 \mathrm{~b}$ \\
\hline $\mathbf{7}$ & $5.50 \pm 0.61 \mathrm{ab}$ & $2.89 \pm 0.71 \mathrm{c}$ & $4.58 \pm 0.55 \mathrm{~b}$ & $13.94 \pm 0.63 \mathrm{c}$ \\
\hline
\end{tabular}

*Means with the same letter are not significantly different according to Tukey Grouping at $5 \%$ level of significant. Note: Column $(\mathrm{a})=$ phase 1 , column $(\mathrm{b})=$ phase 2 , column $(\mathrm{c})=$ phase 3 .

Translating the time taken at each phase (Table 4, column a, b, c and d) into the distance, the coordinate (latitude and longitude) of the drone while flying were extracted from the software. The results are depicted in table (5). Value of column $a, b$ and $c$ are summed up to make a total distance of the travels of the drone (column d). It can be seen from fig. (5) and table (5) (column a, b and c), to reach the target speed of $7 \mathrm{~m} . \mathrm{s}^{-1}$, out of the total length of travel distance in a line, about $26.33 \mathrm{~m}$ was taken in accelerating the speed and about $22.22 \mathrm{~m}$ to decelerate, resulting in the travel distance at a target speed of $7 \mathrm{~m} . \mathrm{s}^{-1}$ being the shortest i.e. $11.22 \mathrm{~m}$. Travel distance at a target speed of 5 m.s ${ }^{-1}$ was a bit higher with $14.67 \mathrm{~m}$, followed by $3 \mathrm{~m} . \mathrm{s}^{-1}$ and $1 \mathrm{~m} . \mathrm{s}^{-1}$ with $31.83 \mathrm{~m}$ and $47.33 \mathrm{~m}$, respectively. Reaching $1 \mathrm{~m} . \mathrm{s}^{-1}$ was the fastest and took the shortest distance to accelerate and decelerate followed by $3 \mathrm{~m} . \mathrm{s}^{-1}$, $5 \mathrm{~m} . \mathrm{s}^{-1}$ and $7 \mathrm{~m} . \mathrm{s}^{-1}$. However, from Table (5) in column (d), it is found that the total travelling distance was not summing up to $56 \mathrm{~m}$ (the set distance), it may be because of the lower frequency (every $0.5 \mathrm{~s}$ ) of the recorded coordinate. Therefore, out of the total travel distance stated in table (5) and column (d), the drone was actually travelling $(\mathrm{m})$ at the target speed set by the ground pilot at only about $21.83 \%$ to $88.98 \%$ from the total flying distance. The percentage value is shown in table (5) and column (e). 
Ismail et al. / Basrah J. Agric. Sci., 34(Special Issue 1): 157-170, 2021

Table (5): Average of travel distance along the line.

\begin{tabular}{cccccc}
\hline $\begin{array}{c}\text { Desired } \\
\text { Speed }\end{array}$ & $\begin{array}{c}\text { Travel } \\
\text { distance by } \\
\text { the drone to } \\
\text { accelerate }\end{array}$ & $\begin{array}{c}\text { Travel } \\
\text { distance by } \\
\text { the drone at } \\
\text { the target } \\
\text { speed }\end{array}$ & $\begin{array}{c}\text { (c) } \\
\text { distance by the } \\
\text { drone to } \\
\text { decelerate }\end{array}$ & $\begin{array}{c}\text { (d) } \\
\text { Total travel } \\
\text { fintance to } \\
\text { line } \\
(\mathrm{a}+\mathrm{b}+\mathrm{c})\end{array}$ & $\begin{array}{c}\text { Per cent } \\
\text { distance of } \\
\text { the drone } \\
\text { flying at } \\
\text { target speed } \\
(\mathrm{b} / \mathrm{d}) * 100) \\
(\%)\end{array}$ \\
\hline $\mathbf{1}$ & $4.11 \pm 2.50 \mathrm{a}$ & $47.33 \pm 3.14 \mathrm{a}$ & $1.75 \pm 1.66 \mathrm{a}$ & $53.19 \pm 2.29 \mathrm{ab}$ & 88.98 \\
\hline $\mathbf{3}$ & $15.39 \pm 2.33 \mathrm{~b}$ & $31.83 \pm 2.78 \mathrm{~b}$ & $6.78 \pm 2.21 \mathrm{~b}$ & $54.00 \pm 1.17 \mathrm{a}$ & 58.95 \\
\hline $\mathbf{5}$ & $19.03 \pm 2.14 \mathrm{c}$ & $14.67 \pm 3.79 \mathrm{c}$ & $12.42 \pm 1.61 \mathrm{c}$ & $53.42 \pm 0.77 \mathrm{a}$ & 27.45 \\
\hline
\end{tabular}

*Means with the same letter are not significantly different according to Tukey Grouping at 5\% level of significant. Note: Column $(\mathrm{a})=$ phase 1 , column $(\mathrm{b})=$ phase 2 , column $(\mathrm{c})=$ phase 3 .

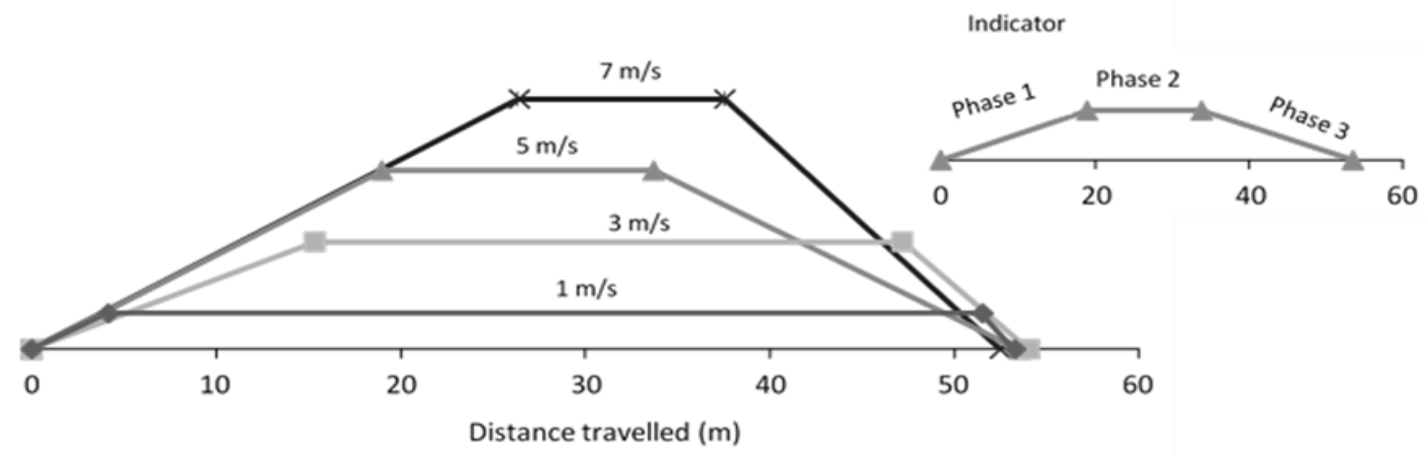

Fig. (5): Distance taken of each phase during flying.

The analysis was further expanded to calculate the theoretical flying time to complete the task in a line if the drone speed was ideal and maintained at the target speed set by the ground pilot. It would be compared with the effective time that the drone actually took in this research. By considering the same travel distance in a line (Table 6, column a), theoretical flying time is calculated by dividing the value in column (a) with the target speed set while the value of effective travelling time had been calculated earlier in table (4) and column (d). It shows that the actual test took longer time to finish the line at percentages of $3.72 \%, 9.24 \%, 23.39 \%$ and
$42.21 \%$ slower than the theoretical time for target speed set at $1 \mathrm{~m} \cdot \mathrm{s}^{-1}, 3 \mathrm{~m} \cdot \mathrm{s}^{-1}, 5 \mathrm{~m} \cdot \mathrm{s}^{-1}$ and $7 \mathrm{~m} . \mathrm{s}^{-1}$ respectively (Table 6 , column d). To finish up the line, it can be seen that the drone was instead flying at the average of $0.96 \mathrm{~m} . \mathrm{s}^{-1}$, $2.72 \mathrm{~m} . \mathrm{s}^{-1}, 3.83 \mathrm{~m} . \mathrm{s}^{-1}$ and $4.05 \mathrm{~m} . \mathrm{s}^{-1}$ for speed set at $1 \mathrm{~m} . \mathrm{s}^{-1}, 3 \mathrm{~m} . \mathrm{s}^{-1}, 5 \mathrm{~m} . \mathrm{s}^{-1}$ and $7 \mathrm{~m} . \mathrm{s}^{-1}$, respectively (Table 6 , column e). The research has proven that knowing the actual travelling pattern of the drone is crucial as the target speed set by the ground pilot would not necessarily reflect the actual speed during operation in the field. It may not be very significant at the set speed of 1 and $3 \mathrm{~m} . \mathrm{s}^{-1}$ as the percentage difference between the set and 
Ismail et al. / Basrah J. Agric. Sci., 34(Special Issue 1): 157-170, 2021

actual speed was less than $10 \%$, but the the set speeds were 5 and $7 \mathrm{~m} \cdot \mathrm{s}^{-1}$ (Table 6, percentage difference was getting higher when column d).

Table (6): Extended calculations of theoretical time, \% slower and average speed.

\begin{tabular}{cccccc}
\hline Target & $\begin{array}{c}\text { (a) } \\
\text { Travel } \\
\text { distance to } \\
\text { finish one } \\
\text { line }\end{array}$ & $\begin{array}{c}\text { Effective } \\
\text { travelling } \\
\text { time to finish } \\
\text { one line }\end{array}$ & $\begin{array}{c}\text { (c) } \\
\text { Theoretical } \\
\text { travelling time } \\
\text { to finish one } \\
\text { line } \\
\text { (a) } / \text { target } \\
\text { speed }\end{array}$ & $\begin{array}{c}\text { d) } \\
\text { Different } \\
\text { percentage } \\
\text { between } \\
\text { effective and } \\
\text { theoretical } \\
\text { travelling time } \\
((\mathrm{b}-\mathrm{c}) / \mathrm{b})^{*} 100\end{array}$ & $\begin{array}{c}\text { (e) } \\
\text { Actual } \\
\text { average } \\
\text { speed across } \\
\text { the line } \\
(\mathrm{b} / \mathrm{a})\end{array}$ \\
\hline $\left.\mathrm{s}^{-1}\right)$ & $(\mathrm{m})$ & $(\mathrm{sec})$ & $(\mathrm{sec})$ & $(\%)$ & \\
\hline 3 & 53.19 & 55.25 & 53.19 & 3.72 & 0.96 \\
\hline 5 & 54.00 & 19.83 & 18.00 & 9.24 & 2.72 \\
\hline 7 & 53.42 & 13.94 & 10.68 & 23.39 & 3.83 \\
\hline 52.47 & 12.97 & 7.50 & 42.21 & 4.05 \\
\hline
\end{tabular}

The delay in catching up the speed is dependent on the abilities of available rotors on the drone. The larger propeller (more than 8-inch diameter) with a lower pitch, paired with motors that have low $\mathrm{kV}$ ratings is normally used for heavier application especially in agriculture. Pitch is defined as the travelling distance per single revolution of the propeller. Larger propeller and lower pitch are important in getting higher torques and less turbulence for lifting besides giving better stability during hovering. However, compared to a smaller propeller, the larger propeller is less responsive and requires more effort in accelerating and decelerating which results in a delay in reaching the earlier set speed by the ground pilot. Up to date, the drones available in the market have their own rotor configurations and specifications, it has been mentioned earlier by Huang et al. (2013) that the industry had lack of standard protocol of UAV development for agricultural applications. This is supported by $\mathrm{He}$ et al. (2017) that highlighted that there are about 178 types of agricultural UAV in the whole nation of China alone that has their own configurations. Due to this, the performance of the drone might be different from what is obtained in this study. It is recommended that each UAV be tested in determining the optimum operation parameter to achieve optimum spray droplet deposition (Lan et al., 2017).

\section{Effect of effective speed on application rate}

The travelling pattern of the drone determined the application rate $\left(1 . \mathrm{ha}^{-1}\right)$ of the drone. The application rate of the drone is important to be known as it will be calibrated with the recommended quantity of the pesticide in ensuring the efficacy of the pesticide. The formula from Eq. (2) was used to estimate the application rate. The example data shown in table (7) is constructed to show how the application speed influenced drone application rate value $\left(1 . \mathrm{ha}^{-1}\right) .5 \mathrm{~m} . \mathrm{s}^{-1}$ of speed was put as an ideal speed while $3.83 \mathrm{~m} . \mathrm{s}^{-1}$ was the actual speed of the drone (Table 6).

It can be seen that the value of the estimated application rate is significant between both 


\section{Ismail et al. / Basrah J. Agric. Sci., 34(Special Issue 1): 157-170, 2021}

sets with a difference of $81 . h a^{-1}$. The actual speed of the drone should be implied in estimating the application rate of the drone, otherwise, the plant will receive an overdose of pesticide along the way.

Furthermore, with the information from fig. (5), for example, if the quantity of pesticide were added according to the estimated application rate when the set speed was $5 \mathrm{~m} . \mathrm{s}^{-}$
1 , according to the calculation in column (e) of table (5), only $27.45 \%$ of the area would be applied with the correct dose while the other $72.55 \%$ of the area might receive an overdose of pesticide. This would incur a significant input cost to the farmer. Determining the actual speed of the drone is necessary before determining any management decision.

Table (7): Drone flying technical specifications.

\begin{tabular}{lcc}
\hline \multicolumn{1}{c}{ Details } & $\begin{array}{c}\text { Drone flying at } \\
\text { target speed }\end{array}$ & $\begin{array}{c}\text { Drone flying at } \\
\text { actual speed }\end{array}$ \\
\hline Pay load $(\mathrm{kg})$ & 10 & 10 \\
\hline Total flow rate $\left(1 . \mathrm{min}^{-1}\right)$ & 2.28 & 2.28 \\
\hline Application height $(\mathrm{m})$ & 2 & 2 \\
\hline Application speed $\left(\mathrm{m} . \mathrm{s}^{-1}\right)$ & 5.00 & 3.83 \\
\hline Swath width, $(\mathrm{m})$ & 3 & 3 \\
\hline Estimated Application rate $\left(\mathbf{l . h a}^{-\mathbf{1}}\right)$ & $\mathbf{2 5 . 3 3}$ & $\mathbf{3 3 . 0 6}$ \\
\hline
\end{tabular}

The other option of having a stable speed while working at the field is by excluding the known distance of Phase 1 and 3 out from the treated field (Fig. 6) by referring to the distance that has been shown in table (5). This option gives a solution in having stable target speed set by the ground pilot in a treated area, so that the plant may receive the same amount of pesticide during operation. Thus, it is recommended to set an offset path before starting points and after the end points to maintain the target speed on the treated area during the actual spraying operation. However, although the treated area will get a uniform rate of pesticide (due to the uniform speed of drone), looking at the drone performance, it is expected to have low field capacity. This is due to the large time lost in Phase 1 and Phase 3. However, this method could possibly be used for the lower-rated speed due to the rapid response of the drone in accelerating and decelerating (Tables 4 and 5). This may bring down the lost time value at Phase 1 and Phase 2 which consequently may bring up the value of field capacity. Besides that, this method may demand another setting to activate and deactivate the sprayer once it enters into and out of the treated area.

In addition, it needs to be noted that the expectation of field capacity mentioned above is not included the time percentage of other processes such as ground service, failure rates and other preparation that would bring down the value of field capacity of the UAV. It is thus necessary to reduce time percentage of other processes in order to increase the working efficiency of UAV (Wang et al. (2017). 


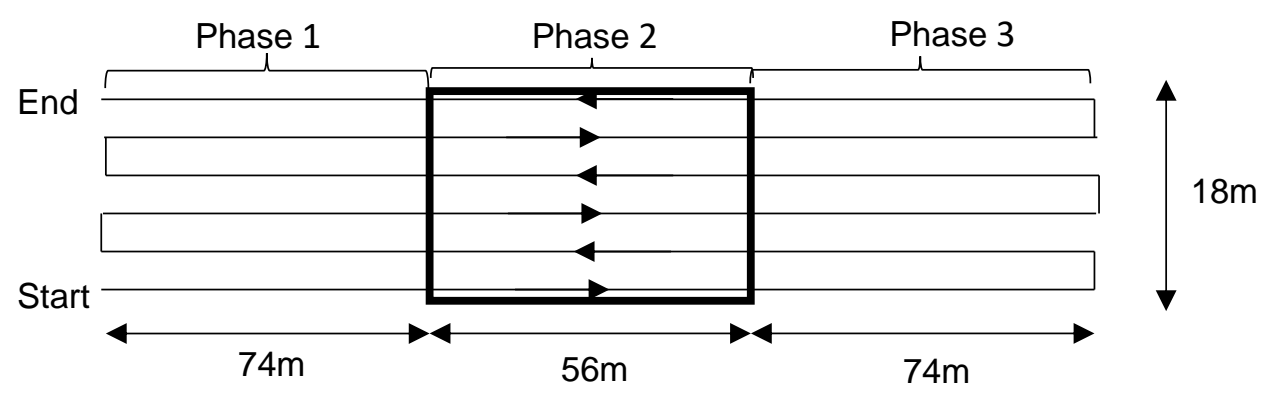

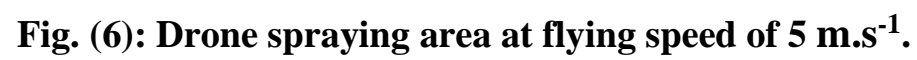

\section{Conclusion}

The research has observed the RPM of the rotors and the travelling pattern of the agricultural drone at a different load and speed. From the findings:

1-The RPM of the rotors responded significantly as the loads and speed changed. In actual spraying operation, the changes of the payload from a full tank to empty tank during spraying would consequently change the RPM of the blades. This would consequently vary the downwash airflow which is expected to affect the distribution uniformity of the quantity of droplets that subsided on the plants along the way.

2-The travelling pattern of the drone is very important in estimating the application rate of the drone itself. The actual average speed of the drone during operation was not reflecting the earlier target speed set by the ground operator due to its response in creating phase in accelerating to reach and decelerating from the target speed resulting in the average speed lower than the target speed.

3-In percentage, the drone was actually travelling $(\mathrm{m})$ at the target speed set by the ground pilot at only about $21.83 \%$ to $88.98 \%$ from the total flying distance in one line.

4-It is suggested that the average of the actual speed is taken as a baseline in estimating the application rate of the drone or otherwise the plant will receive an overdose of pesticide along the way and this would incur a significant input cost to the farmer.

5-To maintain the target speed during operation, the acceleration and deceleration phases need to be excluded from the treated area so that the quantity of pesticide can be accurately applied. It is recommended to set an offset path before starting points and after the end points to maintain the target speed on the treated area during the actual spraying operation.

6-To achieve a high quality of application, a proper dosage of pesticide should be applied evenly, it should reach the plant as a target at proper droplet size and density. Close attention should be focused on managing the drone as the application technology in order to increase the quality of the spraying.

\section{Acknowledgements}

The authors would like to acknowledge the technical support provided by Advansia Sdn. Bhd. Thanks to the Ministry of Higher Education of Malaysia for providing fund under the Fundamental Research Grant Scheme (FRGS/1/2018/WAB01/UPM/02/2). Thank you to SEARCA for providing scholarship under the SEARCA Postgraduate Scholarship Program.

\section{Conflicts of interest}




\section{Ismail et al. / Basrah J. Agric. Sci., 34(Special Issue 1): 157-170, 2021}

The authors declare that they have no conflict of interests.

\section{References}

Berner, B. (2018). Estimation of liquid deposition on plants sprayed from a drone. $4^{\text {th }}$ Workshop on Applied and Sustainable Engineering. Koszalin University of Technology, Poland. https://mendelnet.cz/pdfs/mnt/2018/01/85.pdf

Berner, B., Chojnacki, J. (2017). Use of drones in crop protection. In Proceedings of IX International Scientific Symposium Farm Machinery and Processes Management in Sustainable Agriculture. Lublin. $46-$ 51. https://doi.org/ 10.24326/fmpmsa.2017.9

Doruchowski G., (2013). Challenges and advances in pesticide application technology. Communications in Agricultural and Applied Biological Sciences, 78, 35.

Faiçal, B.S., Pessin, G., Ueyama, J., Freitas, H., Gomes, P.H., Mano, L.Y., Carvalho, A., Krishnamachari, B. (2017). An adaptive approach for UAV-based pesticide spraying in dynamic environments. Computers and Electronics in Agriculture 138, 210223. https://doi.org/ 10.1016/j.compag.2017.04.011

Giles, D. K., \& Billing R. (2014). Unmanned aerial platforms for spraying: Deployment and performance. Aspects of Applied Biology .12. 63-69. https://www.cabdirect.org/cabdirect/abstract/201430 73873

He, X. K., Bonds, J., Herbst A., \& Langenakens J. (2017). Recent development of unmanned aerial vehicle foor plant protection in East Asia. International Journal of Agricultural and Biological Engineering, $\quad 10, \quad 18-30 . \quad$ https://doi.org/ 10.3965/j.ijabe.20171003.3248

Huang, Y, B., Hoffmann, W. C., Lan, Y., Wu, W., \& Fritz, B. K., (2009). Development of a spray system for an unmanned aerial vehicle platform. Appl. Eng. $\begin{array}{llll}\text { Agric. } & 25, & 803- & 809 .\end{array}$ https://core.ac.uk/download/pdf/188134805.pdf

Huang, Y. B., Thomson, S. J., Hoffmann, W. C., Lan, Y. B., \& Fritz, B. K. (2013). Development and prospect of unmanned aerial vehicle technologies for agricultural production management. International Journal of Agricultural and Biological Engineering, $6,1-10$.

Ismail, S. A., Yahya, A., Mat Su, A. S., Asib, N., \& Mohd, M. A. (2019). Chemical spraying using
Unmanned Aerial System (UAS) in wetland rice cultivation in Malaysia. 2019 ASABE Annual International Meeting. Paper Number: 1902854. https://elibrary.asabe.org/abstract.asp?aid=50682 $\& \mathrm{t}=3 \&$ redir $=\&$ redirType $=$

Lan, Y. B., Chen, S. D., \& Fritz, B. K. (2017). Current status and future trends of precision agricultural aviation technologies. International Journal of Agricultural and Biological Engineering, 10, 117.

Meivel, S., Maguteeswaran, R., Gandhiraj, N., \& Srinivasan, G., (2016). Quadcopter UAV based fertilizer and pesticide spraying system. International Academic Research Journal of Engineering Sciences, 1, 8-.12.

Morley, C. G., Broadley, J., Hartley, R., Herries, D., McMorran, D., \& McLean, I. G., (2017).The potential of using unmanned aerial vehicles (UAVs) for precision pest control of possums (Trichosurus vulpecula). Rethinking Ecology, 2, 27-39. https://doi.org/ 10.3897/rethinkingecology.2.14821

Qin, W. C., Qiu, B. J., Xue X. Y., Chen C. Xu Z. F., \& Zhou Q. O. (2016). Droplet deposition and control effect of insecticides sprayed with an unmanned aerial vehicle against plant hoppers. Crop Protection, 85, 79-88'. https://doi.org/10.1016/j.cropro.2016.03.018

Su, A. S. M., Yahya, A., Mazlan, N., \& Hamdani, M. S. A. (2018). Evaluation of the spraying dispersion and uniformity using drone in rice field application. Malaysian Society of Agriculture Engineers (MSAE) Conference of Universiti Putra Malaysia.https://elibrary.msae.my/papers/volume -1/issue-1/evaluation-of-the-spraying-dispersionand-uniformity-using-drone-in-rice-fieldapplication/

Teske M. E., Wachspress D. A., \& Thistle, H. W. (2018). Prediction of aerial spray release from UASs. Transaction of the ASABE, 61, 909-918.

Wang, S. L., Song, J. L., He, X. K., Song, L, Wang, X. N., \& Wang, C. L. (2017). Performances evaluation of four typical unmanned aerial vehicles used for pesticide application in China. International Journal of Agricultural and Biological Engineering, 10, 22-31. https://www.ijabe.org/index.php/ijabe/article/vie wFile/3219/pdf 
Ismail et al. / Basrah J. Agric. Sci., 34(Special Issue 1): 157-170, 2021

Zhang, P., Deng, L., Lyu, Q., He, S. L., Yi, S. L. , Liu, Y., Yu, Y., \& Pan, H. (2016). Effect of Citrus tree shape and spraying height of small unmanned aerial vehicle on droplet distribution. International Journal of Agricultural and Biological Engineering, 9, 45-51. https://ijabe.org/index.php/ijabe/article/view/217 8
Zhang, S. C., Xue, X. Y., Sun, Z., Zhou, L. X., \& Jin, Y. K. (2017). Downwash distribution of single rotor unmanned agricultural helicopter on hovering state. International Journal of Agricultural and Biological Engineering, 10, 1424.

https://ijabe.org/index.php/ijabe/article/view/307 9 